\title{
Anesthetic management of obese and morbidly obese parturients
}

Received August 13, 2021

Revised August 31, 2021

Accepted September 1, 2021

\section{Corresponding author}

Sang Tae Kim, M.D., Ph.D.

Department of Anesthesiology and

Pain Medicine, College of Medicine,

Chungbuk National University, and

Chungbuk National University

Hospital, 776, 1sunhwan-ro, Seowon-

gu, Cheongju 28644, Korea

Tel: 82-43-269-6237

Fax: 82-43-269-6238

E-mail: kimst@chungbuk.ac.kr

\section{Sang Tae Kim}

Department of Anesthesiology and Pain Medicine, College of Medicine, Chungbuk National University, Chungbuk National University Hospital, Cheongju, Korea

The prevalence of obese parturients is increasing worldwide. This review describes safe analgesic techniques for labor and anesthetic management during cesarean sections in obese parturients. The epidural analgesic technique is the best way to provide good pain relief during the labor phase and can be easily converted to a surgical anesthetic condition. However, the insertion of the epidural catheter in obese parturients is technically more difficult compared to that in non-obese parturients. The distance from the skin to the epidural space increases in proportion to the body mass index (BMI): $4.4 \mathrm{~cm}$ in mothers of normal weight and $7.5 \mathrm{~cm}$ in mothers with BMI 50 and above. Neuraxial blocks are the ideal anesthetic methods and gold standard techniques for cesarean section in pregnant women with obesity. Single-shot spinal anesthesia is the most common type of anesthesia used for cesarean sections. The advantage of single-shot spinal anesthesia is a dense-sufficient block of rapid onset. A combined spinal-epidural (CSE) anesthetic technique is also recommended as an attractive alternative method. In obese parturients, the operation time can be longer than expected, and therefore, the CSE technique provides the advantage of rapid onset and intense block for prolonged operation with postoperative pain control. The risk of postoperative complications is very high in obese parturients. Therefore, detailed communication of the parturient's medical condition and the details of surgery and anesthesia between the anesthesiologist and obstetrician is important prior to cesarean section in obese pregnant women.

Keywords: Analgesia; Anesthesia; Morbid obesity; Pregnancy.

\section{INTRODUCTION}

The prevalence of obesity is increasing worldwide, and with dietary and lifestyle changes, the number of obese people in Korea is on the rise. According to statistics, 28 percent of the Korean female population is obese, and the proportion of obese pregnant women is also increasing [1]. Obesity is classified based on the body mass index (BMI, $\mathrm{kg} / \mathrm{m}^{2}$ ), and a BMI over 30 is defined as "obesity." The World Health Organization divides obesity into three classes based on BMI, that is, Class $1: 30.0$ to $34.9 \mathrm{~kg} / \mathrm{m}^{2}$, Class $2: 35.0$ to $39.9 \mathrm{~kg} / \mathrm{m}^{2}$, and Class 3: $\geq 40 \mathrm{~kg} / \mathrm{m}^{2}$ [2]. Some argue that among Asians, including Koreans, different standards of BMI should be applied compared to Westerners', but the present study does not consider the difference in BMI between races, which is beyond the scope of this study [3]. Obesity is classified as a high-risk factor with changes in the respiratory and cardiovascular systems, especially in pregnant women. It also causes problems in anesthetic management due to an increased risk of cesarean section, technical difficulties associ-

This is an Open Access article distributed under the terms of the Creative Commons Attribution Non-Commercial License (http://creativecommons.org/licenses/by-nc/4.0) which permits unrestricted non-commercial use, distribution, and reproduction in any medium, provided the original work is properly cited.

Copyright (C) the Korean Society of Anesthesiologists, 2021 
ated with regional anesthesia, and airway problems related to general anesthesia. Obese parturients should try to control their weight during pregnancy so that they do not reach an obese level because obesity increases the risk to both the fetus and the mother. The weight-gain recommendation guidelines (Table 1) are presented according to the BMI level before pregnancy, and weight control through exercise and diet control leads to safe delivery by preventing obesity [4]. The weight gap between delivery and self-reported pre-pregnancy is defined as the gestational weight gain (GWG). Although GWG as an indicator is reportedly more effective, BMI is a more common and universal method for clinical application, and thus, BMI is more commonly used in practice. This review describes safe analgesic techniques for labor and anesthetic management of cesarean sections in obese parturients.

\section{GENERAL CHARACTERISTICS}

\section{Definition}

BMI is the most common statistical tool used to assess obesity. The weight and height are required for BMI calculations and are typically determined using the weight and height measured in the clinical setting or the self-reported weight and height of individuals. BMI is the weight divided by height $(\mathrm{kg} /$ $\mathrm{m}^{2}$ ). Obesity is defined based on the World Health Organization's international classification of adult BMI; individuals with a BMI $\geq 30$ are obese. This classification of BMI is used in individuals of the white, black, and Hispanic races. There is some debate about the World Health Organization classification because the cut-off values underestimate the risk of obesity in Asian and South Asian populations. In Asian and South Asian populations, some investigators insist that the cut-off value of BMI should be 25 or higher [5].

\section{Prevalence}

In Korean women, the frequency of obesity above BMI 25 is reported to be 28.1 percent for women aged 19 and older and 30.4 percent for women aged 30 and older [1]. Although lower than the percentage of obese women reported in Western countries, this increase in the number of obese women has been pointed out as a threat to the health of pregnant women and fetuses. The exact figure for the proportion of obese people among pregnant women in Korea is yet to be determined, however, it is estimated to be increasing.

\section{Physiologic changes}

\section{Respiratory system}

Pregnancy affects the oxygenation and ventilation of parturients, and the physical, mechanical, and hormonal changes associated with pregnancy bring lead to changes to the respiratory tract. In obese parturients, obstructive sleep apnea is not uncommon, but pregnancy itself has some protective effect on sleep apnea despite nasal passage edema and hyperemia. In the early stages of pregnancy, increased sensitivity of the respiratory center reduces apneic events, and in the second half of pregnancy, parturients tend to lie on their sides and sleep, reducing the possibility of airway obstruction. Long-lasting hypoxemia, hypercapnia, and pulmonary hypertension in obese parturients significantly increase maternal morbidity and mortality $[6,7]$. Despite being a lower abdominal surgery, cesarean sections can lead to reduced lung capacity and volume in obese parturients compared to non-obese parturients [8]. Weight increase in pregnancy further increases the breathing workload, and obese parturients need more energy to move their weight-bearing chest walls during ventilation. The increased abdominal weight limits the movement of the diaphragm, which intensifies in the supine and Trendelenburg positions, reducing the tidal volume. Fortunately, not all changes related to pregnancy in patients with obesity are harmful. The respiratory function can be slightly improved in parturients [9]. In particular, the functional residual capacity is improved. Hormonal changes reduce airway resistance through the relax-

Table 1. Institute of Medicine Guidelines for Weight Gain during Pregnancy in Women with Singletons

\begin{tabular}{lcc}
\hline \multicolumn{1}{c}{ Pre-pregnancy BMI } & Total weight gain $(\mathrm{kg})$ & Rate of weight gain in the 2nd and 3rd trimesters \\
\hline Low $\left(<19.8 \mathrm{~kg} / \mathrm{m}^{2}\right)$ & $12.5-18$ & $0.5 \mathrm{~kg} / \mathrm{wk}$ \\
Normal $\left(19.8-26.0 \mathrm{~kg} / \mathrm{m}^{2}\right)$ & $11.5-16$ & $0.4 \mathrm{~kg} / \mathrm{wk}$ \\
High $\left(26.0-29.0 \mathrm{~kg} / \mathrm{m}^{2}\right)$ & $7-11.5$ & $0.3 \mathrm{~kg} / \mathrm{wk}$ \\
Obese $\left(\geq 29.0 \mathrm{~kg} / \mathrm{m}^{2}\right)$ & $\geq 7$ & Not specified \\
\hline
\end{tabular}

BMI: body mass index $\left(\mathrm{kg} / \mathrm{m}^{2}\right)$. Modified from the book of Institute of Medicine Committee (Nutrition during pregnancy: part I, weight gain; part II, nutrient supplements 1990: 5-10) [4]. 
ation effects of progesterone on smooth muscles, reducing some of the negative effects of obesity on the respiratory system $[10,11]$. While studies have shown that the respiratory effects of obesity are minimal in sitting positions during pregnancy, supine positions can change the volume, flow, and mechanical characteristics of respiration.

\section{Cardiovascular system}

A wide range of cardiovascular changes can occur as the oxygen demand increases during pregnancy, and the pathological changes caused by obesity have serious effect on cardiac, endothelial, and vascular functions. Pregnancy has a rather favorable effect on the respiratory system, while more serious side effects are seen in the cardiovascular system. Pregnancy can worsen previous obesity-related endocrine, inflammatory, and microvascular changes [12]. The degree of secondary cardiovascular pathological changes in obesity depends on the duration and severity of obesity [13]. Excessive extra fat increases the cardiac output. The increase in cardiac output is $30-50 \mathrm{ml} / \mathrm{min}$ for every $100 \mathrm{~g}$ of fat accumulated in the body. Therefore, the blood volume of obese parturients increases accordingly. The volume load initially leads to left ventricular hypertrophy, after which the myocardium begins to expand due to the increased pressure overload. The heart rate increases with the increased cardiac output, decreasing the diastolic interval and myocardial perfusion time. Damaged myocardial diastolic relaxation further leads to myocardial relaxation. Fat deposition in myocardial tissues can have a serious effect on conduction and contractility. Therefore, systolic or diastolic dysfunction can occur frequently in the left ventricle. Patients with pulmonary hypertension and obstructive sleep apnea may experience right ventricular impairment. Congestive heart failure is a result of additional stress [14]. The effect of the enlarged uterus compressing major blood vessels in the abdomen and causing supine hypotensive syndrome (SHS) can also be seen in obese parturients. This can worsen significantly in obese parturients, where a large panniculus with an enlarged uterus exacerbates uterine compression. This problem can be extended after surgery if the panniculus is large enough to compress the blood vessels. There have been reported cases of postoperative sudden cardiac arrest in morbidly obese surgical patients that remain unexplained after autopsy. The autopsies showed no pathology to explain the cardiac arrest in such cases [15].

\section{Gastrointestinal system}

The anatomical and hormonal changes associated with pregnancy increase the incidence and severity of gastric reflux in parturients. Obesity increases the risk of gastric aspiration under general anesthesia, and hiatal hernia may be more common in obese parturients. When pregnancy is associated with obesity, the chances of regurgitation and aspiration increase significantly. Some researchers have reported that the gastric volume of obese parturients is five times greater than that of non-obese parturients in labor [16].

\section{Diseases associated with morbid obesity in pregnancy}

Diabetes and hypertension are common problems during pregnancy. Continuous inflammation and pregnancy-related hormonal changes in obese patients worsen blood glucose levels. Major complications reported to be related to obesity during pregnancy include hypertension, diabetes mellitus, respiratory disease, thromboembolic disorders, infections, and an increased risk of postpartum hemorrhage. The association between obesity and hypertension, diabetes mellitus, and an increased incidence of cesarean section is well known $[17,18]$. In addition, labor-related complications such as an increased rate of instrumental delivery, failure to progress, intrapartum fetal distress, meconium aspiration, abnormal fetal presentation, and shoulder dystocia are common in obese parturients [19]. Furthermore, the success rate of vaginal delivery after cesarean surgery has been shown to decrease proportionally with increased maternal BMI $[20,21]$. The incidence of post-delivery endometriosis and wound infections is considerably higher in obese patients [19]. Obesity itself is a high-risk factor for both increased delivery-related blood loss and postpartum hemorrhage [22]. A meta-analysis showed that the odds ratios of a cesarean section in obese parturients were 1.46 (overweight, 95\% confidence interval [CI]: 1.34-1.60), 2.05 (obese, 95\% CI: 1.862.27 ), and 2.89 (severely obese, 95\% CI: 2.28-3.79), relatively higher than that in normal weight pregnant women [23]. According to the literature, obese parturients have a $14-25 \%$ prevalence of preeclampsia, a $6-14 \%$ prevalence of gestational diabetes, and a $30-47 \%$ incidence of cesarean sections [17]. Parturient obesity is highly associated with an increased risk of fetal macrosomia, fetal death, and birth defects [2426]. Many studies have reported an increased risk of neural tube defects, omphalocele, fetal heart defects, and multiple anomalies [25]. In addition, obesity itself makes it difficult to detect fetal anomalies in the early stages with diagnostic ultrasound. The high incidence of fetal anomalies in morbidly 
obese parturients may be due to the inability to adequately evaluate the fetus because of maternal obesity and underlying maternal medical diseases such as preeclampsia and diabetes mellitus.

\section{ANESTHETIC MANAGEMENT}

Obese pregnant women have a high incidence of comorbid diseases, and therefore, they need to be thoroughly evaluated and prepared before anesthesia at an early stage. An appropriate-sized blood pressure cuff should be used for noninvasive blood pressure measurements because if the width of the cuff is relatively small compared to the arm circumference, the blood pressure measurement can show higher values. Therefore, the blood pressure cuff is sometimes applied on the mother's forearm to avoid this problem. The blood pressure with forearm measurements correlate well with the upper arm measurements, but exceed an average of $10 \mathrm{mmHg}$. Conical noninvasive blood pressure cuffs for obese patients were introduced and used in clinical settings and are known to correlate well with measured arterial blood pressure values [27]. If blood pressure measurements using noninvasive blood pressure methods do not reflect the actual blood pressure, invasive blood pressure measurements using intra-arterial catheters may be more useful. Obesity can cause difficulties in securing intravenous lines; therefore, appropriate veins should be secured early in delivery. If a peripheral venous line cannot be secured, intravenous cannulation under ultrasonic guidance or the central vein should also be considered. Sufficient manpower is essential for the transport of obese patients. In addition, beds, mobile carts, and operating tables that can withstand proper size and weight are also checked in advance. Sufficient pads may be required to place obese patients on labor beds or operating tables, and a long spinal or epidural Tuohy needle may be required.

\section{Analgesia for labor}

Analgesia for labor is effective and important for a good outcome of the fetus and good satisfaction of the parturient. Neuraxial analgesia is effective and useful for reducing labor pain in parturients. For obese mothers, the epidural analgesic technique is the best and safest way to provide labor analgesia [28]. It is the best way to provide a good pain relief effect during the labor phase, and can be easily converted to surgical anesthetic conditions in the case of cesarean sec- tion, if required. Since the incidence of fetal macrosomia is high, epidural analgesia can help in the successful management of shoulder dystocia. Therefore, frequent evaluation for well-functioning epidural catheters is extremely important to verify that the epidural method can be reliably extended to provide appropriate surgical anesthesia, if required. However, the insertion of the epidural catheter in obese parturients is technically more difficult compared to that in non-obese parturients. Anesthesiologists have more difficulties in the identification of the midline in the lumbar spine, detection of epidural space, and placement of epidural catheters in obese parturients. Knee-chest positioning in the lateral decubitus is comparatively more difficult to sustain in the obese parturient than in the non-obese group. Gravity in the lateral decubitus position can also force the panniculus down, which obscures the midline of the lumbar spine. For this reason, the sitting position is preferred to easily locate the midline for epidural catheterization. More objectively, the midline can be identified under ultrasound, and the epidural space can be found using images to measure the depth from the skin to the epidural space. In pregnant women, ultrasound imaging before epidural catheterization can significantly reduce the number of attempts and help identify the correct intervertebral space and epidural depth. However, viewing ultrasound images is more difficult in obese parturients, and the fact that all anesthesiologists are not familiar with using ultrasound is still considered a limitation. The distance from the skin to the epidural space increases in proportion to BMI: $4.4 \mathrm{~cm}$ in mothers of normal weight and $7.5 \mathrm{~cm}$ in BMI 50 and above [29] (Table 2). Therefore, even in obese parturients, a typical Tuohy needle can be used to identify the epidural space; therefore, it is preferable to use a standard-length epidural Tuohy needle at first, which can be

Table 2. Mean Depth from the Skin to the Lumbar Epidural Space

\begin{tabular}{cccc}
\hline \multicolumn{1}{c}{ Variable } & Mean \pm SD & Median & Range \\
\hline BMI & & & \\
$<25$ & $4.40 \pm 0.81$ & 4.5 & $3.0-7.0$ \\
$25-29$ & $4.80 \pm 0.85$ & 5.0 & $3.0-11.0$ \\
$30-34$ & $5.30 \pm 0.93$ & 5.0 & $3.0-10.0$ \\
$35-39$ & $6.2 \pm 1.2$ & 6.0 & $3.0-10.5$ \\
$40-44$ & $6.6 \pm 1.3$ & 7.0 & $3.0-11.0$ \\
$45-49$ & $7.2 \pm 1.2$ & 7.5 & $4.0-11.0$ \\
$>50$ & $7.5 \pm 1.2$ & 7.5 & $5.0-11.0$ \\
Mean depth for all BMI & $5.3 \pm 1.2$ & 5.0 & $3.0-11.0$ \\
\hline
\end{tabular}

BMl: body mass index $\left(\mathrm{kg} / \mathrm{m}^{2}\right)$. Modified from the article of Clinkscales et al. (Int J Obstet Anesth 2007; 16: 323-7) [29]. 
easier for anesthesiologists, but a longer Tuohy needle may be needed in some parturients. The medication and techniques for labor analgesia in obese parturients are not significantly different from those in mothers of normal weight. Patient-controlled epidural analgesia (PCEA) and programmed intermediate epidural boluses are widely used and dilute low concentrations of local anesthetics $(<0.1 \%$ bupivacine or equivalent potency of ropivacaine) mixed with opioids (fentanyl or sufentanil) are recommended as medications [30].

\section{Anesthesia for cesarean section}

Anesthesiologists need thorough preparation, especially in obese parturients, prior to cesarean section. In particular, anesthesiologists should evaluate parturient airways completely prior to general anesthesia. Even if neuraxial anesthesia is performed, a thorough evaluation of the airway is needed because the anesthetic technique can be converted to general anesthesia due to inadequate sensory blockade or prolonged operation time. In obese pregnant women, intubation and manipulation of blade handling can be difficult because of the large breasts, increased anterior-posterior chest diameter, airway swelling, and shortening of the jaw and chest spacing. When laboring mothers present to the operating room for cesarean section, many staff members are required to move the parturient from the ward bed to the operating table. In the presence of a neuraxial blockade, it is difficult to safely bring an obese mother to the operating table. This shift poses a potential risk of injury to both the parturient and the staff supporting this transition. It can be very difficult to properly and safely position obese pregnant women in a surgical bed for a cesarean section, which must be supplied with right wedges for left-uterus displacement. In addition, medical staff must securely fasten the obese parturient to the bed to prevent falls before tilting to the left. However, it is more important to position the left uterus as soon as possible because SHS appears relatively faster and can be more serious than that in normal-weight pregnant women. Pulling the panniculus toward the head of a morbidly obese pregnant woman can cause pressure on the upper abdomen and chest, reducing venous return and cardiac output, resulting in hypotension.

\section{Regional anesthesia}

Neuraxial blocks are the ideal anesthetic method and gold standard technique for cesarean section in obese pregnant women. There are three anesthetic techniques: spinal, epidural, and combined spinal-epidural (CSE). Single-shot spinal anesthesia is the most common type of anesthesia used for cesarean sections. The advantage of single-shot spinal anesthesia includes a dense, sufficient block of rapid onset. However, the associated problems include technical difficulties in obese women, potential risk for high spinal blockade, profound dense thoracic motor blockade leading to suppression of cardiorespiratory function, and inability to prolong the duration of anesthesia. Neuraxial anesthesia is very difficult in obese women because of the marked adipose tissue on the spine and the difficulty in palpating the spinous process [31]. A critical step for success in performing neuraxial anesthesia is the identification of the midline. The advantage of a midline approach in spinal or epidural anesthesia is that the success rate is high, and the provider can easily feel the needle tip through engagement in the supraspinous ligament. In cases where the midline approach is not used, a paramedian approach may be used. In a paramedian approach, there are no tactile advantages with respect to the location of the needle tip, as the needle is located in the para-spinous muscle and not the supraspinous ligament. It is widely accepted that local anesthetic requirements for neuraxial anesthesia are lower in pregnant women and in obese women. Obesity increases intra-abdominal pressure and causes compression of the inferior vena cava, which leads to the engorgement of the epidural venous plexus and increases the pressure of the epidural space. This mechanism reduces the cerebrospinal fluid volume in the subarachnoid space. Therefore, some anesthesiologists insist that the dose regimen should be adjusted in obese parturients, with the aim of achieving appropriate surgical anesthesia while minimizing hemodynamic complications. However, many researchers have reported that dose reduction in obese patients may not be recommended [32-34]. They reported that the ED50 of bupivacaine for successful spinal anesthesia in morbidly obese mothers was $9.8 \mathrm{mg}$, similar to the other reports in the non-obese group [32]. There were no significant differences in the incidence of nausea, vomiting, and phenylephrine dose requirement [32]. However, many anesthesiologists are concerned about high spinal anesthesia in a morbid obesity parturient, and single-shot spinal anesthesia with a pencil point needle may be technically difficult. Therefore, a CSE anesthetic technique is recommended as an attractive alternative method. Placing an epidural Tuohy needle may be easier than a spinal needle insertion and 
can be used as a guide for the spinal needle as a needle through the needle CSE method. In an obese parturient, the operation time can be longer than expected, and therefore, the CSE technique provides the advantage of rapid onset and intense block for prolonged operation with postoperative pain control. In addition, a lower dose of intrathecal bupivacaine can be administered, and the level of block can be adjusted with an epidural catheter to achieve adequate surgical anesthesia. In parturients with severe cardiovascular disease, a lower dose of intrathecal bupivacaine and slowly titrated local anesthetics lead to minimal hemodynamic changes, and therefore, a sudden onset of hypotension may be prevented effectively. CSE has a beneficial effect on obese parturients with cardiovascular diseases.

\section{General anesthesia}

In Korea, approximately $28.8 \%$ of cesarean sections have been performed under general anesthesia over the past five years [35], but the rate of general anesthesia limited to the obese parturient group has not yet been reported. The rate of general anesthesia in Korea is significantly higher than that in Western countries [36]. Considering that the fatal complication rate is high under general anesthesia, if possible, it would be desirable to replace general anesthesia with regional anesthesia. Owing to the anatomic and physiologic changes in obese mothers, difficult intubation and urgent desaturation can occur in such patients. Therefore, proficient assistance may be needed to maintain airways. The jaw-thrust maneuver can also require the use of both hands of the anesthesiologists, and therefore, other staff may be needed for positive pressure ventilation and downward pressing on the cricoid cartilage. Various equipment (such as laryngoscope with short blades, supraglottic airway devices, video laryngoscope, fiberoptic intubation devices, Bullard laryngoscope, or cricothyrotomy devices) should be prepared for difficult intubation situations. If intubation fails, the intubation failure algorithm must be started, and help must be requested immediately [37]. If intubation is expected to be difficult, rapid sequence induction is recommended, and during apnea, pregnant women fall into hypoxia faster, with obese mothers reaching hypoxia even faster; therefore, sufficient preoxygenation should be performed before initiating general anesthesia. Proper parturient positioning for the best laryngoscopic view can assist in securing a difficult airway. The ramped position improves the laryngoscopic view compared to the traditional sniffing position and can be accomplished by elevating the head of an obese parturient above the shoulders by modifying the operating table or by applying blankets under the upper body [38,39] (Fig. 1). As soon as the parturient is transferred to the operating table, the facial mask is firmly fixed to the face, and oxygen administration begins subsequently. Preoxygenation is an essential process for delaying the desaturation of obese mothers and providing sufficient oxygen. The dosage of induction anesthetics in obese women should be calculated based on the ideal body weight rather than the actual weight [40]. Succinylcholine and rocuronium are widely used as neuromuscular blockers for rapid tracheal intubation during general anesthesia. One study attempted to determine the appro-
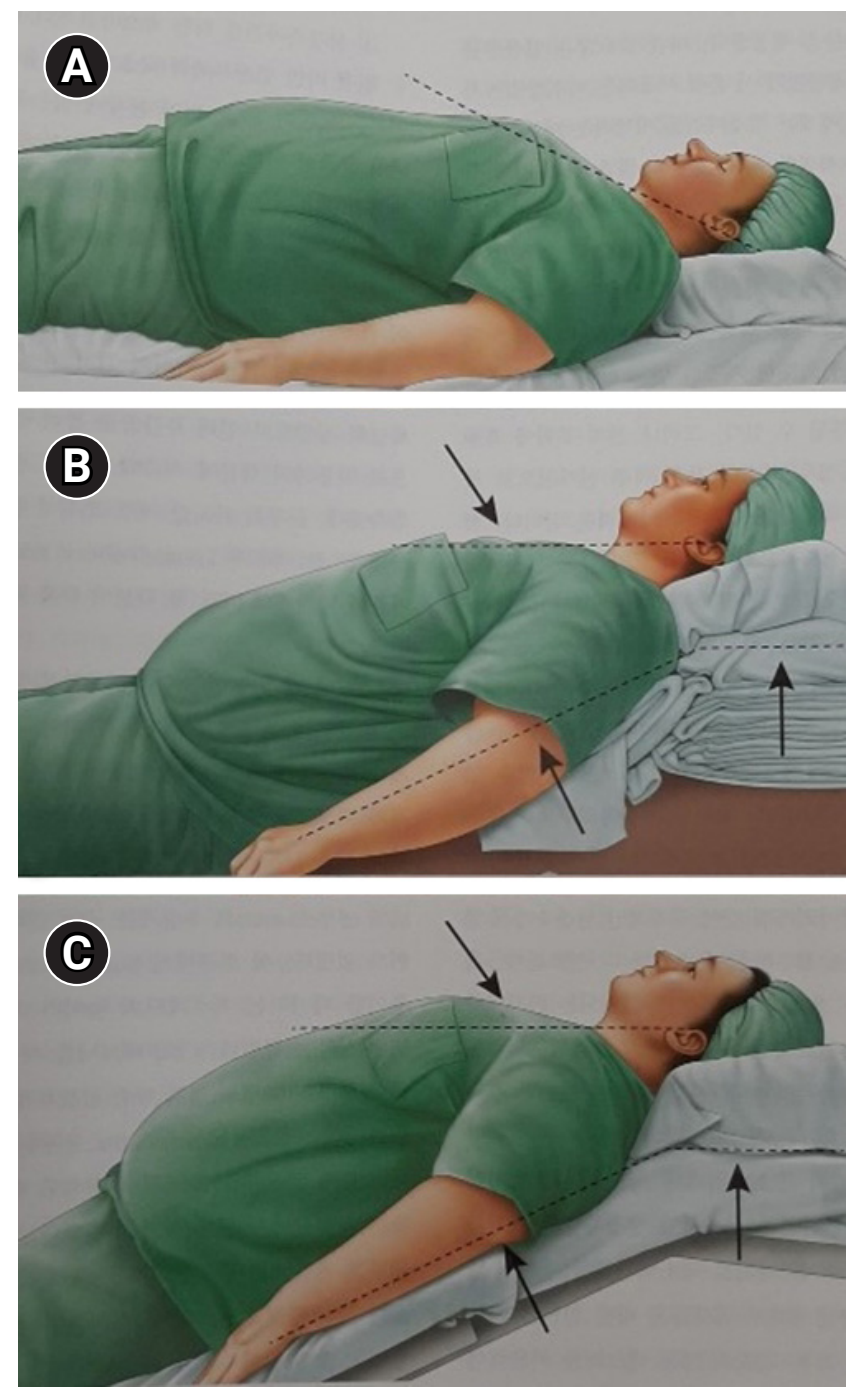

Fig. 1. Comparison of positions suitable for tracheal intubation in morbidly obese parturients. (A) Sniffing position. (B) Ramped position (by applying blankets under the upper body). (C) Ramped position (by modifying the operating table). Modified from the book of The Korean Society of Obstetric Anesthesiologist (Obstetric anesthesia 2016: 351-4) [39]. 
priate dose of succinylcholine for the ideal intubating condition in the non-pregnant morbidly obese group, concluding that $1.0 \mathrm{mg} / \mathrm{kg}$ based on the total body weight provides both complete paralysis and satisfactory intubating conditions [41]. Alternatively, rocuronium may be administered to provide an adequate laryngoscopic condition at a dose of $1-1.2 \mathrm{mg} / \mathrm{kg}$ based on ideal body weight [42]. Sugammadex can be administered to reverse the neuromuscular blocking induced by rocuronium or vecuronium in a short time [43]. In the supine position under general anesthesia, early closure of small airways due to decreased functional residual capacity, administration of volatile anesthetics, neuromuscular blockers, and cephalad retraction of the panniculus may lead to pulmonary hypoxemia. Many interventions (high tidal volumes, high inspired oxygen, and the use of positive end-expiratory pressure) have been used to maintain appropriate arterial oxygenation. Tracheal extubation should only be attempted in fully awake parturients with appropriate reversal of neuromuscular blockers, as failed extubation may occur easily in obese parturients [44]. A $30^{\circ}$ head-up tilting is an excellent position for tracheal extubation in obese patients compared to a simple supine position [45].

\section{Postoperative management}

The risk of postoperative complications (hypoxemia, pulmonary atelectasis, deep vein thrombosis, pulmonary edema, postpartum cardiomyopathy, and wound complications) is very high in the obese parturient group [46]. Moreover, a BMI-dependent decrease in respiratory function may occur even after regional anesthesia [47]. Postoperative pulmonary events may lead to severe complications. Therefore, postoperative early ambulation has also been reported to improve respiratory function during the postoperative period [47]. In morbidly obese parturients, postpartum complications occur after cesarean section and do not occur after vaginal delivery [44]. Postoperative pain should be properly controlled and reduced to facilitate postoperative mobilization and lung care because postoperative pulmonary complications are very important determinants of prognosis. PCEA with dilute local anesthetics mixed with opioids may improve the quality of postoperative pain relief. The risk factor of thrombosis is associated with pregnancy, cesarean section, and obesity, and postoperative pulmonary thromboembolism remains a major cause of maternal mortality. Both pharmacological and mechanical interventions can be used for prophylaxis; therefore, perioperative use of an ade- quate anticoagulant and intermittent pneumatic compression are recommended [48]. In obese parturients, postoperative wound complications occur more frequently than in the non-obese group, which often leads to prolonged recovery and long hospitalization, and the midline vertical abdominal incision is associated with a higher incidence of wound complications than a Pfannenstiel incision [49]. Morbidly obese parturients may be hospitalized for significantly longer duration because of the increased incidence of postoperative complications and antepartum medical disease. The length of hospital stay and costs in morbidly obese parturients have been shown to increase after both vaginal delivery and cesarean operations [50].

\section{CONCLUSIONS}

The high prevalence of obese parturients may lead to maternal and fetal morbidity and can also increase the incidence of side effects from labor, cesarean section, and anesthesia; therefore, careful evaluation and preparation before delivery and surgery is needed in such cases. Prior to the cesarean section for obese parturients, detailed communication between the anesthesiologist and obstetrician regarding the parturients' medical condition and details of surgery and anesthesia for the parturient should be established. Neuraxial anesthetic techniques are the gold standard method in morbid parturients, but neuraxial anesthesia may be converted to general anesthesia because of the prolonged operation time or technical failure; therefore, airway evaluation and equipment for airway assistance must be in place at all times. For rapid recovery from surgery, adequate postoperative pain control and an adjusted anticoagulant dose for an appropriate duration are recommended. Careful observation of airway obstruction is required in morbid parturients because respiratory depression after delivery and obstructive sleep apnea can occur in such cases.

\section{CONFLICTS OF INTEREST}

No potential conflict of interest relevant to this article was reported.

\section{DATA AVAILABILITY STATEMENT}

Data sharing not applicable to this article as no datasets were generated or analyzed during the current study. 


\section{ORCID}

Sang Tae Kim, https://orcid.org/0000-0001-9315-2107

\section{REFERENCES}

1. KOSIS. The trend in the prevalence of obesity (BMI). Statistics Korea [serial on the Internet]. [2021 May 20]. Available from https: / / kosis.kr/statHtml/statHtml.do? orgId = 177\&tblId=DT_11702_N101\&conn_path = I2.

2. Obesity: preventing and managing the global epidemic. Report of a WHO consultation. World Health Organ Tech Rep Ser 2000; 894: i-xii, 1.

3. Jee SH, Sull JW, Park J, Lee SY, Ohrr H, Guallar E, et al. Bodymass index and mortality in Korean men and women. N Engl J Med 2006; 355: 779-87.

4. Institute of Medicine (US) Committee on Nutritional Status during Pregnancy and Lactation. Nutrition during pregnancy: part I weight gain: part II nutrient supplements. Washington D.C., National Academies Press (US). 1990, pp 5-10.

5. WHO Expert Consultation. Appropriate body-mass index for Asian populations and its implications for policy and intervention strategies. Lancet 2004; 363: 157-63.

6. Lefcourt LA, Rodis JF. Obstructive sleep apnea in pregnancy. Obstet Gynecol Surv 1996; 51: 503-6.

7. Lewis DF, Chesson AL, Edwards MS, Weeks JW, Adair CD. Obstructive sleep apnea during pregnancy resulting in pulmonary hypertension. South Med J 1998; 91: 761-2.

8. von Ungern-Sternberg BS, Regli A, Schneider MC, Kunz F, Reber A. Effect of obesity and site of surgery on perioperative lung volumes. Br J Anaesth 2004; 92: 202-7.

9. Eng M, Butler J, Bonica JJ. Respiratory function in pregnant obese women. Am J Obstet Gynecol 1975; 123: 241-5.

10. Unterborn J. Pulmonary function testing in obesity, pregnancy, and extremes of body habitus. Clin Chest Med 2001; 22: 759-67.

11. Knuttgen HG, Emerson K Jr. Physiological response to pregnancy at rest and during exercise. J Appl Physiol 1974; 36: 549-53.

12. Ramsay JE, Ferrell WR, Crawford L, Wallace AM, Greer IA, Sat$\operatorname{tar}$ N. Maternal obesity is associated with dysregulation of metabolic, vascular, and inflammatory pathways. J Clin Endocrinol Metab 2002; 87: 4231-7.

13. Vasan RS. Cardiac function and obesity. Heart 2003; 89: 1127-9.

14. Tomoda S, Tamura T, Sudo Y, Ogita S. Effects of obesity on pregnant women: maternal hemodynamic change. Am J Perinatol 1996; 13: 73-8.

15. Drenick EJ, Fisler JS. Sudden cardiac arrest in morbidly obese surgical patients unexplained after autopsy. Am J Surg 1988;
155: $720-6$

16. Linné Y, Barkeling B, Rössner S. Natural course of gestational diabetes mellitus: long term follow up of women in the SPAWN study. BJOG 2002; 109: 1227-31.

17. Weiss JL, Malone FD, Emig D, Ball RH, Nyberg DA, Comstock $\mathrm{CH}$, et al. FASTER Research Consortium. Obesity, obstetric complications and cesarean delivery rate--a population-based screening study. Am J Obstet Gynecol 2004; 190: 1091-7.

18. Sheiner E, Levy A, Menes TS, Silverberg D, Katz M, Mazor M. Maternal obesity as an independent risk factor for caesarean delivery. Paediatr Perinat Epidemiol 2004; 18: 196-201.

19. Usha Kiran TS, Hemmadi S, Bethel J, Evans J. Outcome of pregnancy in a woman with an increased body mass index. BJOG 2005; 112: 768-72.

20. Durnwald CP, Ehrenberg HM, Mercer BM. The impact of maternal obesity and weight gain on vaginal birth after cesarean section success. Am J Obstet Gynecol 2004; 191: 954-7.

21. Carroll CS Sr, Magann EF, Chauhan SP, Klauser CK, Morrison JC. Vaginal birth after cesarean section versus elective repeat cesarean delivery: weight-based outcomes. Am J Obstet Gynecol 2003; 188: 1516-20; discussion 1520-2.

22. Andreasen KR, Andersen ML, Schantz AL. Obesity and pregnancy. Acta Obstet Gynecol Scand 2004; 83: 1022-9.

23. Chu SY, Kim SY, Schmid CH, Dietz PM, Callaghan WM, Lau J, et al. Maternal obesity and risk of cesarean delivery: a meta-analysis. Obes Rev 2007; 8: 385-94.

24. Ehrenberg HM, Mercer BM, Catalano PM. The influence of obesity and diabetes on the prevalence of macrosomia. Am J Obstet Gynecol 2004; 191: 964-8.

25. Watkins ML, Rasmussen SA, Honein MA, Botto LD, Moore CA. Maternal obesity and risk for birth defects. Pediatrics 2003; 111(5 Pt 2): 1152-8.

26. Stephansson O, Dickman PW, Johansson A, Cnattingius S. Maternal weight, pregnancy weight gain, and the risk of antepartum stillbirth. Am J Obstet Gynecol 2001; 184: 463-9.

27. Hersh LT, Sesing JC, Luczyk WJ, Friedman BA, Zhou S, Batchelder PB. Validation of a conical cuff on the forearm for estimating radial artery blood pressure. Blood Press Monit 2014; 19: 38-45.

28. Anim-Somuah M, Smyth RM, Cyna AM, Cuthbert A. Epidural versus non-epidural or no analgesia for pain management in labour. Cochrane Database Syst Rev 2018; 5: CD000331.

29. Clinkscales CP, Greenfield ML, Vanarase M, Polley LS. An observational study of the relationship between lumbar epidural space depth and body mass index in Michigan parturients. Int J Obstet Anesth 2007; 16: 323-7.

30. Nanji JA, Carvalho B. Modern techniques to optimize neuraxial 
labor analgesia. Anesth Pain Med 2018; 13: 233-40.

31. Butcher M, George RT, Ip J, Campbell JP, Yentis SM. Identification of the midline by obese and non-obese women during late pregnancy. Anaesthesia 2014; 69: 1351-4.

32. Carvalho B, Collins J, Drover DR, Atkinson Ralls L, Riley ET. $\mathrm{ED}(50)$ and $\mathrm{ED}(95)$ of intrathecal bupivacaine in morbidly obese patients undergoing cesarean delivery. Anesthesiology 2011; 114: 529-35.

33. Ngaka TC, Coetzee JF, Dyer RA. The influence of body mass index on sensorimotor block and vasopressor requirement during spinal anesthesia for elective cesarean delivery. Anesth Analg 2016; 123: 1527-34.

34. Lee Y, Balki M, Parkes R, Carvalho JC. Dose requirement of intrathecal bupivacaine for cesarean delivery is similar in obese and normal weight women. Rev Bras Anestesiol 2009; 59: 67483.

35. Park JI, Park SH, Kang MS, Kang GW, Kim ST. Evaluation of changes in anesthetic methods for cesarean delivery: an analysis for 5 years using the big data of the Korean Health Insurance Review and Assessment Service. Anesth Pain Med (Seoul) 2020; 15: 305-13.

36. Traynor AJ, Aragon M, Ghosh D, Choi RS, Dingmann C, Vu Tran Z, et al. Obstetric anesthesia workforce survey: a 30-year update. Anesth Analg 2016; 122: 1939-46.

37. Mushambi MC, Kinsella SM, Popat M, Swales H, Ramaswamy KK, Winton AL, et al. Obstetric Anaesthetists' Association; Difficult Airway Society. Obstetric Anaesthetists' Association and Difficult Airway Society guidelines for the management of difficult and failed tracheal intubation in obstetrics. Anaesthesia 2015; 70: 1286-306.

38. Rao SL, Kunselman AR, Schuler HG, DesHarnais S. Laryngoscopy and tracheal intubation in the head-elevated position in obese patients: a randomized, controlled, equivalence trial. Anesth Analg 2008; 107: 1912-8.

39. The Korean Society of Obstetric Anesthesiologists. Obstetric anesthesia. 2nd ed. Paju, Koonja. 2016, pp 351-4.

40. Ingrande J, Lemmens HJ. Dose adjustment of anaesthetics in the morbidly obese. Br J Anaesth 2010; 105 Suppl 1: i16-23.

41. Lemmens HJ, Brodsky JB. The dose of succinylcholine in morbid obesity. Anesth Analg 2006; 102: 438-42.

42. Meyhoff CS, Lund J, Jenstrup MT, Claudius C, Sørensen AM, Viby-Mogensen J, et al. Should dosing of rocuronium in obese patients be based on ideal or corrected body weight? Anesth Analg 2009; 109: 787-92.

43. Pühringer FK, Rex C, Sielenkämper AW, Claudius C, Larsen PB, Prins ME, et al. Reversal of profound, high-dose rocuronium-induced neuromuscular blockade by sugammadex at two different time points: an international, multicenter, randomized, dose-finding, safety assessor-blinded, phase II trial. Anesthesiology 2008; 109: 188-97.

44. Hood DD, Dewan DM. Anesthetic and obstetric outcome in morbidly obese parturients. Anesthesiology 1993; 79: 1210-8.

45. Vaughan RW, Bauer S, Wise L. Effect of position (semirecumbent versus supine) on postoperative oxygenation in markedly obese subjects. Anesth Analg 1976; 55: 37-41.

46. Rose DK, Cohen MM, Wigglesworth DF, DeBoer DP. Critical respiratory events in the postanesthesia care unit. Patient, surgical, and anesthetic factors. Anesthesiology 1994; 81: 410-8.

47. von Ungern-Sternberg BS, Regli A, Bucher E, Reber A, Schneider MC. Impact of spinal anaesthesia and obesity on maternal respiratory function during elective Caesarean section. Anaesthesia 2004; 59: 743-9.

48. Kim ST. Perioperative pulmonary embolism. Korean J Anesthesiol 2009; 56: 245-53.

49. Wall PD, Deucy EE, Glantz JC, Pressman EK. Vertical skin incisions and wound complications in the obese parturient. Obstet Gynecol 2003; 102(5 Pt 1): 952-6.

50. Galtier-Dereure F, Montpeyroux F, Boulot P, Bringer J, Jaffiol C. Weight excess before pregnancy: complications and cost. Int J Obes Relat Metab Disord 1995; 19: 443-8. 